\title{
Effects of Thermal Processing on Transparent Conducting Oxides (TCO) Used in Optoelectronic Devices
}

\author{
Zakia Fekkai \\ Department of Physics, Al Imam Mohammad Ibn Saud Islamic University, Riyadh 11623, Saudi Arabia
}

Received: June 05, 2012 / Accepted: July 08, 2012 / Published: March 25, 2013.

\begin{abstract}
Due to its high electrical conductivity and high transparency in the visible light wavelength range, transparent conductive oxide thin films are able to be used as semiconductor materials on electronic devices. Among these films/materials, zinc oxides ( $\mathrm{ZnO}$ ), indium oxides $\left(\mathrm{In}_{2} \mathrm{O}_{3}\right)$ and tin oxide thin films $\left(\mathrm{SnO}_{2}\right)$ which are particularly attractive due to their optical, electrical and mechanical properties. In this investigation, the metal oxide films were prepared by pulsed laser deposition technique (PLD) using the same deposition parameters. The electrical, structural, and optical properties of these films were examined. The resistivity of the films were calculated based on the sheet resistance $R_{s}$ measured by the standard four-point probe technique at room temperature. Concerning the structural properties, all films presented uniform, dense and smooth surface. The films were annealed for 1 hour at different temperatures $\left(200-600{ }^{\circ} \mathrm{C}\right)$ in an argon atmosphere. Annealing greatly decreased the resistivity of the films. Atomic Force microscopy (AFM) measurements revealed an increase in surface roughness of the annealed films with temperature. Improvement to the crystallinity_was observed from the double layers $\left(\mathrm{SnO}_{2}\right) /(\mathrm{ZnO})$ annealed at $300-400{ }^{\circ} \mathrm{C}$ and above with a slight decrease in the optical transmittance. The transmittance of these films was measured in the spectrum range 200-2,000 nm using a spectrophotomer. High transmittance above (85\%) in the visible region was exhibited by the films annealed at $400{ }^{\circ} \mathrm{C}$ and above. A lower resistivity and better spectra selectivity is a measurement of the quality and potential use of indium/tin oxides onto intrinsic zinc oxide deposited on cleaned glass substrates, for the application as transparent electrodes of electronic devices such as solar cells and organic light- emitting diodes.
\end{abstract}

Key words: Transparent conducting oxides, optical properties, annealing, pulsed laser deposition, optoelectronic devices.

\section{Introduction}

Among various functional thin film materials, metal oxides are particularly attractive due to their unique properties covering all aspects of material science and solid state physics. Tin oxide $\left(\mathrm{SnO}_{2}\right)$ is one of the most important metal oxides. $\mathrm{SnO}_{2}$ is a transparent n-type semiconductor having a wide optical band gap of 3.8 eV.

Due to various properties, tin oxide is suitable for a number of applications such as transparent electrodes for solar cells, liquid crystal displays, highly active catalysts, anodes for lithium ion batteries, transistors,

Corresponding author: Zakia Fekkai, assistant professor, research fields: polymer physics, OLED and applied materials. E-mail: zakiafekkai@hotmail.co.uk. nano \& ultra filtration membranes, gas sensors, anti corrosion coatings, etc.

In recent years, there has been an increase in the number of applications of $(\mathrm{ZnO})$, indium oxides $\left(\mathrm{In}_{2} \mathrm{O}_{3}\right)$ and tin oxide thin films $\left(\mathrm{SnO}_{2}\right)$ thin films, due to their unique optical, electrical and mechanical properties which are different to those of bulk material. All these metal oxides are n-type transparent semiconductors with a wide optical band gap in the range $\left(E_{g}=3.8-4\right.$ $\mathrm{eV})$. These properties have led them to play an irreplaceable and increasing role in many areas of today's very demanding and rapidly developing technology, especially in the electronic displays and optical industries [1-3].

Interest in transparent films with an oxide layer such as $(\mathrm{ZnO}),\left(\mathrm{In}_{2} \mathrm{O}_{3}\right)$ and $\left(\mathrm{SnO}_{2}\right)$ thin films has increased 
due to its excellent electrical and optical properties for a wide range of applications including heat-reflecting mirrors [4], the field of flat panel displays [3] antireflection coatings [4], organic light-emitting diodes [5], and gas sensors [6], and as transparent electrodes in solar cells [7].

The major concerns for transparent metal oxide films transparent conducting oxides (TCO) deposition are as follows:

- low specific resistivity $\left(<1.50 \times 10^{-6} \Omega \cdot \mathrm{cm}\right)$;

- high uniformity across the substrate;

- low particle contamination;

- low manufacturing costs.

There are several deposition techniques to grow TCO thin films including chemical vapor deposition [11], magnetron sputtering $[12,13]$, evaporation $[6,14]$, spray pyrolysis [15], sol-gel [16] and pulsed laser ablation $[10,17]$. The resulting TCO thin films exhibit low resistivity (ca. $4.2 \times 10^{-4} \Omega \cdot \mathrm{cm}$ ) and high optical transmittance in the visible region (ca. 85\%); and band gap of (3.87-4.78 eV), deposited on a glass substrates.

\section{Experiments}

Pulsed laser deposition (PLD) was used in the preparation of pure $\mathrm{ZnO}, \mathrm{In}_{2} \mathrm{O}_{3}$ and $\mathrm{SnO}_{2}$ thin films onto glass substrates at $400{ }^{\circ} \mathrm{C}$. The films were grown in a typical PLD system that uses an excimer laser beam $\left(\mathrm{KrF}, \lambda=248 \mathrm{~nm}\right.$, laser energy $2 \mathrm{~J} / \mathrm{cm}^{2}$, repetition rate $5 \mathrm{~Hz}$ ) [1, 2]. The materials of deposition targets were commercially available of $99.999 \%$ pure $\mathrm{In}_{2} \mathrm{O}_{3}, \mathrm{SnO}_{2}$ and $\mathrm{ZnO}$. The targets employed during thin film growth were sintered and pressed locally. Prior to film deposition, the $(0.7 \mathrm{~mm}$ thick $)$ glass substrates were cleaned by sonication with detergent (acetone, methanol), rinsed with deionised water for 20 min, blown dry by nitrogen gas and finally dried in the oven at $120{ }^{\circ} \mathrm{C}$ for outgassing. Fig. 1 shows a schematic diagram of the pulsed laser deposition process (PLD).

Immediately after drying, the substrates were transferred to the PLD system for the deposition of zinc oxide materials ( $70 \mathrm{~nm}$ thick ) and then indium or tin oxide layers $(30 \mathrm{~nm})$. The base pressure pressure prior to deposition was approximately $2 \times 10^{-6}$ Torr. Substrate to target distance was $32 \mathrm{~mm}$ and was maintained at the same value for all experiments. Film growth was performed at a temperature of $300{ }^{\circ} \mathrm{C}$ in an oxygen pressure of $10 \mathrm{mTorr}$ for $20 \mathrm{~min}$.

After deposition, the samples were divided into two sets: one for characterization as-deposited and one set to be annealed in an argon atmosphere for $1 \mathrm{~h}$ at various temperatures $\left(200,300,400,500\right.$, and $\left.600{ }^{\circ} \mathrm{C}\right)$, and then charaterized in order to investigate the changes in microstucture or properties if any. Resistivities of the films were measured using a four-point probe configuration/method at room temperature for as-deposited and annealed films. The surface morphology and roughness of the films before and after annealing were observed using atomic force microscopy (AFM) in tapping mode. The structural properties and grain sizes of the grown films were investigated using an AFM.

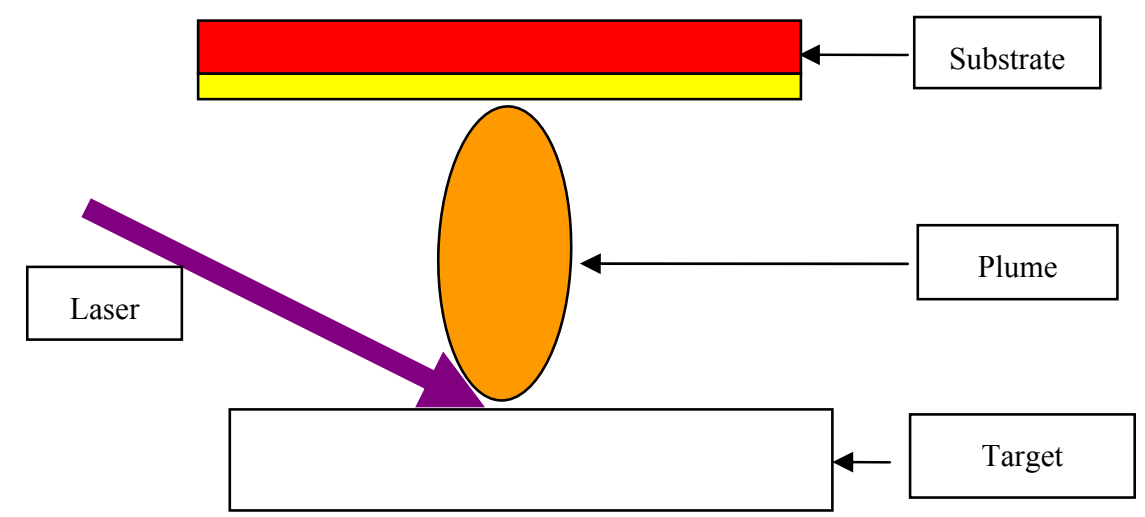

Fig. 1 A schematic diagram of the Pulsed Laser Deposition process. 


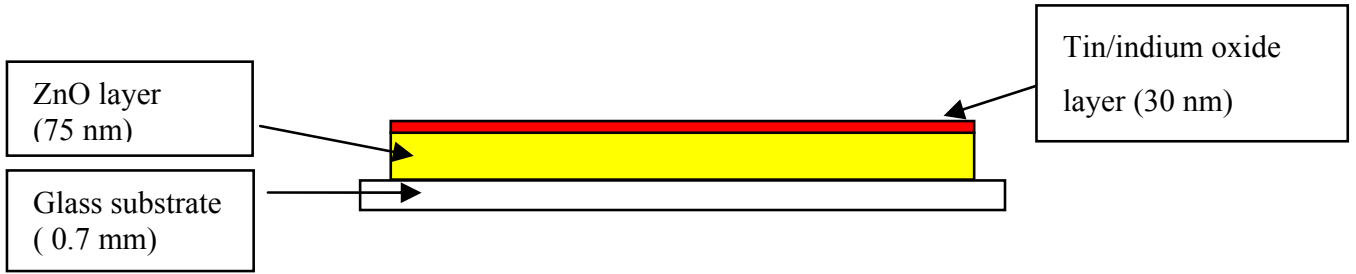

Fig. 2 A cross-sectional view of metal oxide physical interface structure used as an electrode in optoelectronic devices.

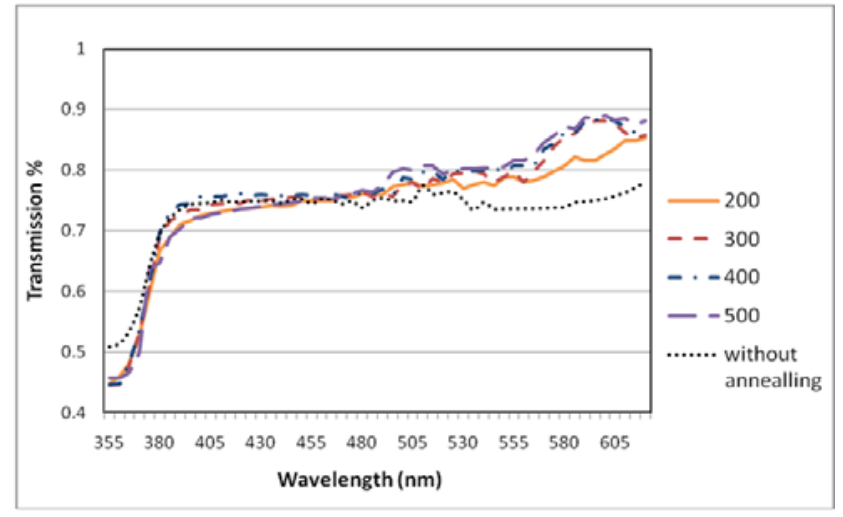

(a)

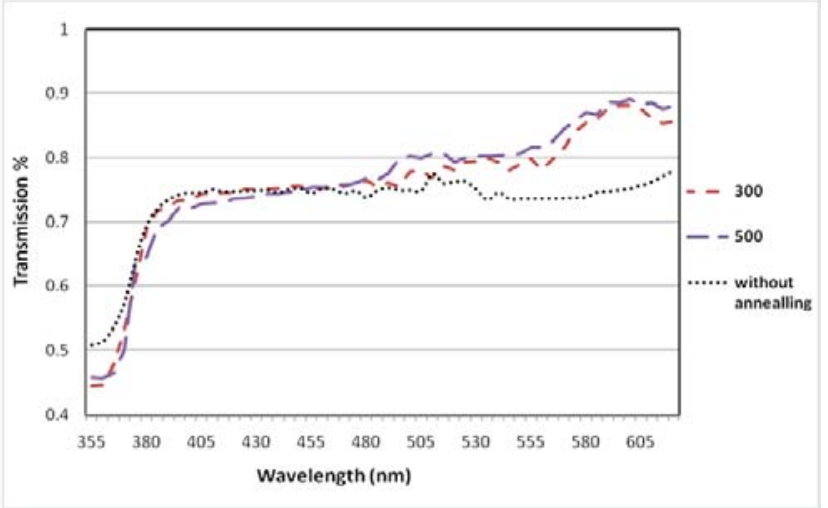

(b)

Fig. 3 The TRansmission spectra of the $\mathrm{ZnO} / \mathrm{In}_{2} \mathrm{O}_{3}$ thin films: (a) for different annealing temperatures; (b) for selective annealing temperatures as a function of wavelength.

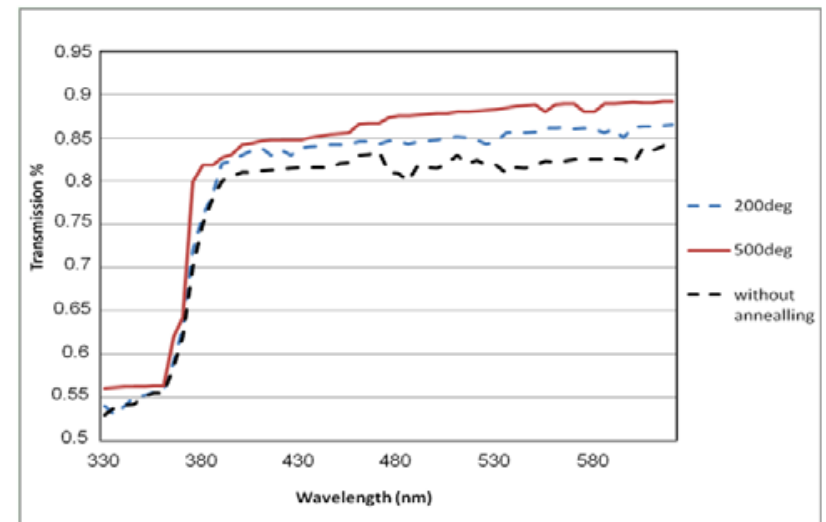

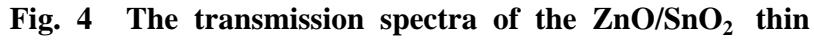
films for different annealing temperatures as a function of wavelength.
The optical transmittance and absorption measurements were performed with an $\mathrm{UV} / \mathrm{V}$ is spectrophotometer. A typical proposed physical interface structure used in our investigation is shown in Fig. 2.

After all the film depositions and during characterization, the nano-structured layers were kept in a nitrogen-filled box to protect them from oxygen and water vapors.

Finally, energy dispersive X-ray spectroscopy (EDX) was used for the elemental analysis or chemical characterization of transparent conducting oxide samples.

\section{Results and Discussion}

\subsection{Optical Properties}

Fig. 3 represents the transmittance in the visible wavelength range from $300 \mathrm{~nm}$ to $800 \mathrm{~nm}$ of a $75 \mathrm{~nm}$ thick $\mathrm{ZnO}: \mathrm{In}_{2} \mathrm{O}_{3}$ thin films. All deposited films showed high transmittance more than $80 \%$. Furthermore, the TCO films show an increase of transmittance with annealing temperature which probably indicates that the annealing treatment improved the crystallinity.

The optical transmission characteristics of $\mathrm{ZnO} / \mathrm{SnO}_{2}$ thin films deposited on glass substrates are shown in Fig. 4. The annealed films showed an increase in the transmission with increased annealing temperatures.

\subsection{Resistivity}

The sheet resistance $R_{s}$ of the TCO films was measured using a four-point probe method at room temperature. By assuming that the thickness of the films was uniform, The resistivity $\rho$ of the films was 
Table 1 Resistivities and band gap values for $\mathrm{SnO}_{2}: \mathrm{ZnO}$ annealed at various temperatures.

\begin{tabular}{lll}
\hline Resistivity $(\Omega \cdot \mathrm{cm}) \times 10^{-4}$ for $\mathrm{SnO}_{2}: \mathrm{ZnO}$ films & Annealing temperature $\left({ }^{\circ} \mathrm{C}\right)$ & Energy gap, $E_{g}(\mathrm{eV})$ \\
\hline 20 & 150 & 3.68 \\
6.4 & 200 & 3.71 \\
5.2 & 250 & 3.78 \\
3.6 & 300 & 3.81 \\
2.6 & 400 & 3.86 \\
2.2 & 500 & 3.91 \\
1.98 & 600 & 4.10 \\
\hline
\end{tabular}

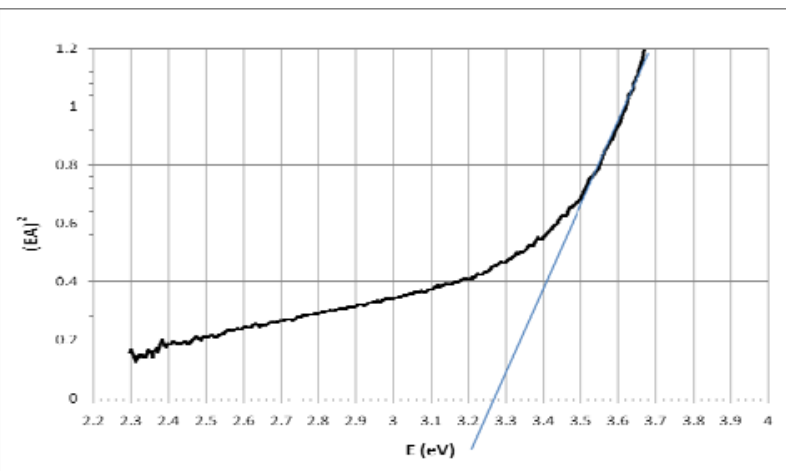

Fig. 5 Plot of (EA) ${ }^{2}$ versus photon energy for $\mathrm{ZnO} / \mathrm{In}_{2} \mathrm{O}_{3}$ films fabricated by annealed at $500{ }^{\circ} \mathrm{C}$.

calculated from the simple equation $\rho=R_{S} d$, where $d$ is the TCO film thickness. A low resistivity of $2.25 \times 10^{-4}$ $\Omega \cdot \mathrm{cm}$ was measured for the $100 \mathrm{~nm}$ thick $\mathrm{SnO}_{2} / \mathrm{In}_{2} \mathrm{O}_{3}: \mathrm{ZnO}$ films at ambient temperature.

Annealed films had lower resistivity than the as -deposited TCO ones ranging from $20 \times 10^{-4} \Omega \cdot \mathrm{cm}$ to $2.2 \times 10^{-4} \Omega \cdot \mathrm{cm}$. Probably due to increase in carrier concentration with the indium/tin oxides entering into the $\mathrm{ZnO}$ lattice caused a shift in absorption edge and the average transmittance increased to $85 \%$ in the visible region. Resistivities and band gap values for $\mathrm{SnO}_{2}: \mathrm{ZnO}$ annealed at various temperatures are shown in Table 1.

The absorption spectra (EA) of the $\mathrm{ZnO}: \mathrm{In}_{2} \mathrm{O}_{3}$ films in the band gap edge region have been obtained from the optical transmission and reflection measurements at room temperature, the energy gap was found to be very similar for the as-deposited and annealed films $\left(E_{g}=\right.$ $3.25 \mathrm{eV})$.

\subsection{Atomic Force Microscopy}

AFM was also used to find surface roughness and grain sizes of the deposited TCO $\left(\mathrm{ZnO} / \mathrm{In}_{2} \mathrm{O}_{3}\right)$ films used as anodes in the optoelectronic devices. Images are provided (Fig. 6) at $20 \mu \mathrm{m}$ magnification for transparent oxide films. The deposited film surfaces were mainly smooth and dense for all the films used, and showed fine crystalline structure, with grain sizes at $300{ }^{\circ} \mathrm{C}$ temperature in the range of 5-6 $\mathrm{nm}$. Smooth and dense anode would enhance its chemical stability, especially when used in long term operation of optoelectronic devices. Fig. 6 shows the AFM images of the surface roughness and morphology of $\mathrm{In}_{2} \mathrm{O}_{3}: \mathrm{ZnO}$ films.

Fig. 7 shows the morphology of $\mathrm{SnO}_{2}: \mathrm{ZnO}$ thin films with small grain sizes of 5-7 $\mathrm{nm}$. It shows a surface roughness of approximately $15 \mathrm{~nm}$. The surface roughness and work function of transparent conducting oxide films are very important to enhance the stability and efficiency of optoelectronic devices such as solar cells and light emitting diodes. All functional active layers of the devices which act as injection, transportation and emission layers are deposited on TCO, so surface morphology of TCO film is directly transferred to them and uneven interface is not desirable for the efficiency and stability of these devices.

\subsection{Energy Dispersive X-Ray Spectroscopy (EDX)}

EDX was used for the elemental analysis or chemical characterization of transparent conducting oxide samples. The EDX characterization results are presented in Fig. 8.

EDX analyses show that $\mathrm{Zn}, \mathrm{O}$ and In elements in the sample $\operatorname{In}_{2} \mathrm{O}_{3} / \mathrm{ZnO}$ present in the solid film. The $\mathrm{Si}$ 


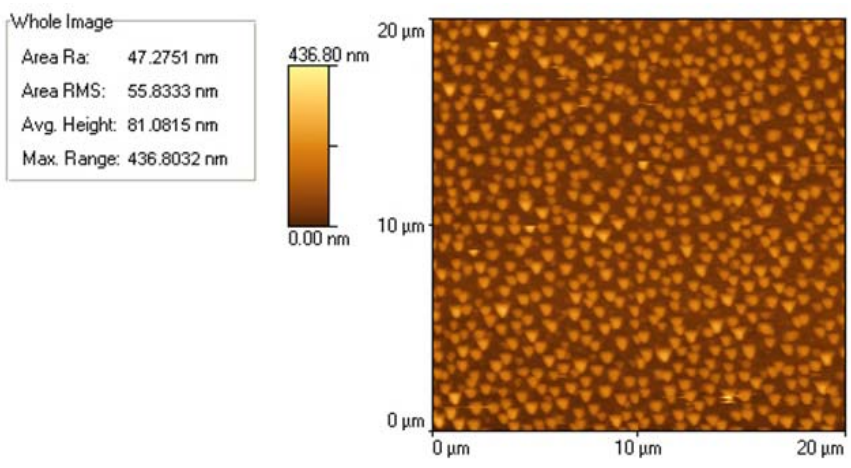

(a)

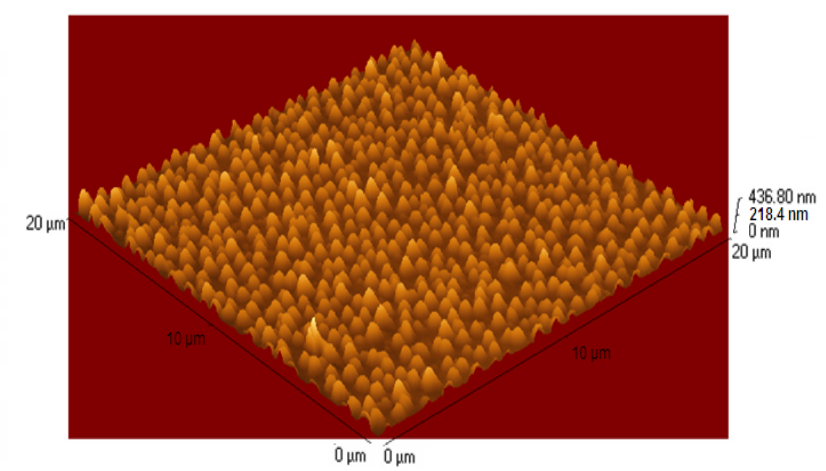

(b)

Fig. 6 AFM images of (a) the Surface of $\operatorname{In}_{2} \mathrm{O}_{3}: \mathrm{ZnO}$ thin film annealed at $300{ }^{\circ} \mathrm{C}$ for 60 minutes with small grains and (b) and roughness of the film.

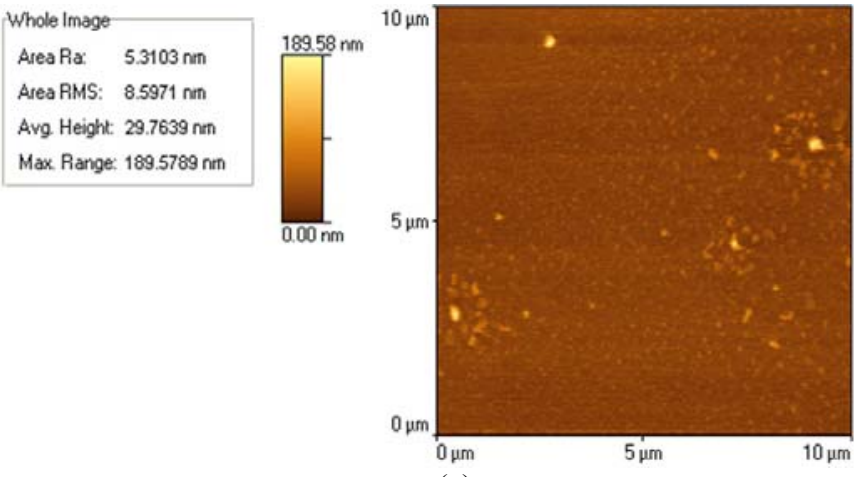

(a)

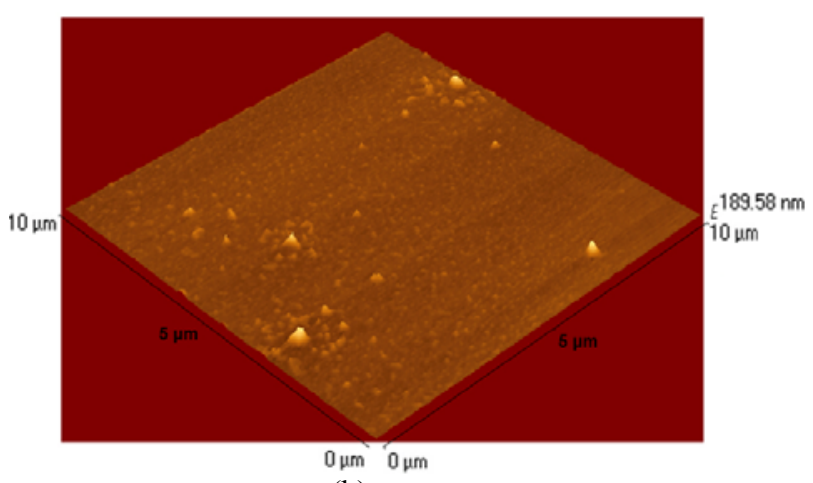

(b)

Fig. 7 AFM images of: (a) the Surface of $\mathrm{SnO}_{2}: \mathrm{ZnO}$ thin film annealed at $300{ }^{\circ} \mathrm{C}$ for 60 minutes with small grains and (b) and roughness of the film. It shows a surface roughness of approximately $15 \mathrm{~nm}$.

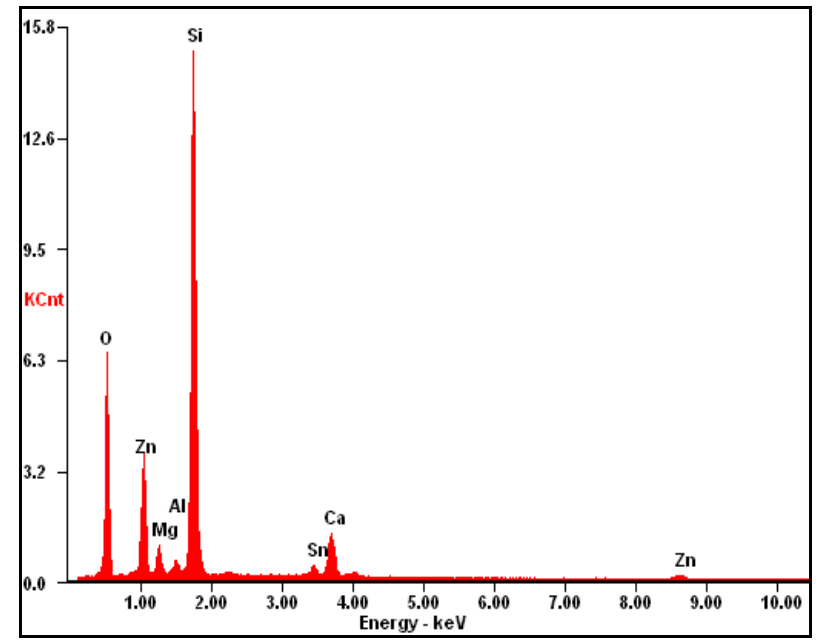

(a)

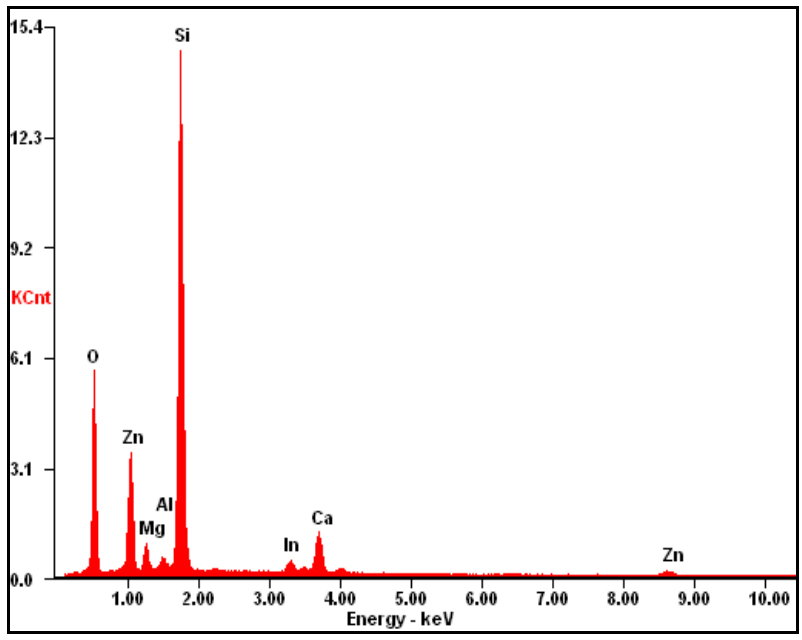

(b)

Fig. 8 EDX spectra of the films: (a) $\mathrm{In}_{2} \mathrm{O}_{3}: \mathrm{ZnO}$ and (b) $\mathrm{SnO}_{2}: \mathrm{ZnO}$.

Table 2 represents the elemental weights in the deposited films.

\begin{tabular}{lllll}
\hline & Zinc $(w t \%)$ & Oxygen $(w t \%)$ & Indium $(w t \%)$ & Tin (wt\%) \\
\hline $\mathrm{In}_{2} \mathrm{O}_{3} / \mathrm{ZnO}$ & 3.8 & 6 & 0.85 & - \\
$\mathrm{SnO}_{2} / \mathrm{ZnO}$ & 3.8 & 0.85 & - & 0.85 \\
\hline
\end{tabular}


$\mathrm{Mg}$, and $\mathrm{Ca}$ elements that are not expected to be in solid films may probably result from the glass substrates. Elemental weights (wt. \%) of Zn, O and Sn elements in the $\mathrm{SnO} / \mathrm{ZnO}$ thin films are listed in Table 2. These spectra show that the expected elements exist in the solid films.

\section{Conclusions}

In summary, this paper presents the fabrication of a nano-structured electrode with highly transparent and conducting oxide (TCO) thin films. It has been proved that TCO thin film with low resistivity (ca. $2.2 \times 10^{-4}$ $\Omega \cdot \mathrm{cm}$ ) and high visible-light-transmittance (ca. $80 \%-85 \%$, band gap, $3.71 \mathrm{eV}$ ) can be achieved on glass substrate using a pulsed laser deposition process. The super-smooth TCO films obtained here are applicable to various optoelectronic devices such as solar cells and organic light emitting diodes.

Annealing the nano-structured film would improve the adhesion of the physical interfaces between the PLD deposited films and the substrate. The atomic force microscopy (AFM) showed an increase in the surface roughness of the annealed films while maintaining high transmittance in the range $80-85 \%$ for the visible region (300-800 $\mathrm{nm})$. Resistivity decreased rapidly for the annealed films.

Highly transparency, good conductivity and super smooth properties of transparent conducting oxide (TCO) thin films are particularly desirable in optoelectronic devices.

\section{Acknowledgments}

The author would like to thank Al-Imam Muhammad Ibn Saud Islamic University for the financial support of this project. The authors would like to thank Dr Samy Mziou for his technical assistance in preparing the manuscript.

\section{References}

[1] M.J. Brett, R.R. Parsons, H.P. Baltes, Zinc oxide multilayers for solar collector coatings, Applied Optics 25 (16) (1986) 2712-2714.
[2] D. Gracin, U. Desnica, Windows with heat mirrors for energy conservation, International Journal of Energy Research 81 (1) (1984) 53-60.

[3] T. Minami, S. Takata, T. Kakumu, New multicomponent transparent conducting oxide films for transparent electrodes of flat panel displays, Journal of Vacuum Science \& Technology A: Vacuum, Surfaces and Films 14 (3) (1996) 1689-1693.

[4] H. Takato, M. Yamanaka, Y. Hayashi, R. Shimokawa, I. Hide, S. Gohda, et al., Effects of optical confinement in textured antireflection coating using $\mathrm{ZnO}$ films for solar cells, Japanese Journal of Applied Physics A 31 (12) (1992) L1665-L1667.

[5] H.J. Bolink, E. Coronado, D. Repetto, M. Sossolo, Air stable hybrid organic-inorganic light emitting diodes using $\mathrm{ZnO}$ as the cathode, Applied Physics Letters 91 (22) (2007) 3501-3504.

[6] H. Nanto, T. Minami, T. Shinzo, Zinc-oxide thin-film ammonia gas sensors with high sensitivity and excellent selectivity, Journal of Applied Physics 60 (2) (1986) 482-484.

[7] K. Matsubara, P. Fons, K. Iwata, A. Yamada, ZnO transparent conducting films deposited by pulsed laser deposition for solar cell applications, Thin Solid Films (2003) 431-432

[8] K.L. Chopra, P.D. Paulson, V. Dutta, Thin-film solar cells: an overview, Progress in Photovoltaics: Research and Applications, Special Issue: Progress in Thin-film Solar Cells 12 (2-3) (2004) 69-92.

[9] H.C. Lee, Electron scattering mechanisms in indium-tin-oxide thin films prepared at the various process conditions, Applied Surface Science 252 (2006) 3428-3435.

[10] G.S. Belo, B.J.P. Da Silva, E.A. De Vasconcelos, W.M. De Azevedo, E.F.J. De Silva, A simplified reactive thermal evaporation method for indium tin oxide electrodes, Applied Surface Science 255 (2008) 755-757.

[11] H. Kim, J.S. Horwitz, G. Kushto, A. Pique, Z.H. Kafafi, C.M. Gilmore, et al., Effect of film thickness on the properties of indium tin oxide thin films, Journal of Applied Physics 88 (10) 2000.

[12] V.S. Vaishnava, P.D. Patel, N.G. Patel, Indium tin oxide thin film gas sensors for detection of ethanol vapours, Thin Solid Films 490 (2005) 94-100.

[13] D. Raoufi, A. Kiasatpour, H.R. Fallah, Surface characterization and microstructure of ITO thin films at different annealing temperatures, Applied Surface Science 253 (2007) 9085-9090.

[14] H. Kim, A. Pique, J.S. Horwitz, H. Mattoussi, H. Murata, Z.H. Kafafi, et al., Indium tin oxide thin films for organic light-emitting devices, Applied Physics Letters 74 (23) (1999) 3444-3446. 

Used in Optoelectronic Devices

[15] K. Maknys, A.G. Ulyashin, H. Stiebig, A.Yu, Kuznetsov, B.G. Svensson, Analysis of ITO thin layers and interfaces in heterojunction solar cells structures by AFM, SCM and SSRM methods, Thin Solid Films 511-512 (2006) 98-102.

[16] M. Nisha, M.K. Jayaraj, Influence of RF power and fluorine doping on the properties of sputtered ITO thin films, Applied Surface Science 255 (2008) 1790-1795.

[17] H. Lei, X.G. Diao, H.Z. Xu, B.X. Gu, T.M. Wang, Thickness dependence of structural, electrical and optical properties of indium tin oxide (ITO) films deposited on PET Substrates, Applied Surface Science 254 (2008) 3504-3508. 